\title{
Estudo da utilização de CaOLi na síntese de biodiesel.
}

\author{
Celeri, E. P. ${ }^{1}$; Barañano, A. G. ${ }^{2}$; Castro, L.S ${ }^{3 *}$. \\ 1Curso de Química Universidade Federal do Espírito Santo, Alegre, ES, Brasil. \\ 2 Programa de Pós-Graduação em Engenharia Química, Universidade Federal do Espírito Santo, Alegre, ES, Brasil. \\ 3 Programa de Pós-Graduação em Engenharia Química, Universidade Federal de Minas Gerais, Belo Horizonte, MG, \\ Brasil.
}

*e-mail: lucienecasttro@hotmail.com

\section{Resumo}

O biodiesel é um combustível derivado de biomassa como óleo vegetal e gordura animal, sendo um combustível promissor substituto ao diesel em virtude de ser renovável e de baixa toxicidade. Neste trabalho foi realizado a síntese de biodiesel isoamílico de óleo de soja utilizando o catalisador heterogêneo óxido de cálcio impregnado com lítio (CaOLi). Os testes catalíticos ocorreram à 25드, 65드 e $110^{\circ} \mathrm{C}$, durante 6 horas. O produto foi verificado qualitativamente através de cromatografia em camada delgada, em que confirmou a formação de biodiesel à $110^{\circ} \mathrm{C}$.

\begin{abstract}
Biodiesel is a fuel derived from biomass such as vegetable oil and animal fat. It is a promising fuel substitute for diesel because of being renewable and low toxicity. In this work the isoamylic biodiesel synthesis of soybean oil was carried out using the heterogeneous lithium-impregnated calcium oxide catalyst (CaOLi). Catalytic tests were performed at $25^{\circ} \mathrm{C}, 65^{\circ} \mathrm{C}$ and $110^{\circ} \mathrm{C}$ for 6 hours. The product was checked qualitatively by thin layer chromatography, confirmed the formation of biodiesel at $110^{\circ} \mathrm{C}$.
\end{abstract}

Keywords (Palavras chaves): biodiesel, catalisador heterogêneo, álcool Isoamílico, CaOLi.

\section{Introdução}

O biodiesel é um biocombustível renovável geralmente obtido pelo método de transesterificação [1], que consiste numa reação entre um triglicerídeos e um álcool na presença de um catalisador formando como produtos biodiesel e a glicerina.[2].

O biodiesel pode ser produzido a partir de diversas oleaginosas, destaca-se o óleo de soja, a principal matéria prima utilizada pelo Brasil na síntese desse combustível [3], [4].

O catalisador utilizado na transesterificação pode ser homogêneo ou heterogêneo. $O$ catalisador homogêneo é mais utilizado, no entanto requer várias lavagens para remoção dos sabões, glicerina e resto do próprio catalisador, necessita de mais equipamentos e geralmente são solúveis o que impossibilita o reuso. Diante disso, surgiu o interesse pelo uso de catalisador heterogêneo, que visa eliminar parcialmente ou totalmente a etapa de lavagem, o reuso e reciclagem do catalisador e facilitar a separação entre os produtos e catalisador [5]. O óxido de cálcio $(\mathrm{CaO})$ destaca-se como catalisador heterogêneo devido a não toxicidade, elevada basicidade, requerer apenas condições moderadas, causa menor impacto ambiental, ter baixa solubilidade no biodiesel e rendimento de biodiesel excelente [6].

A adição de lítio em óxido de cálcio aumentou a atividade catalítica e estabilidade do material [7], que foram testados em diferentes matérias-primas como: soja [8], karanja (Millettia pinnata) [9], pinhão manso [9], girassol[10], (Mesua férrea L., Guttiferae) e algodão [8].

Os álcoois mais utilizados para produção de biodiesel são o metanol e etanol [11]. O álcool isoamílico ainda é pouco explorado para síntese do biodiesel tendo poucos resultados na literatura sobre sua utilização.

Esse álcool pode ser extraído a partir do óleo fúsel [12]. O óleo fúsel é um resíduo obtido da produção de etanol [13], que geralmente são gerados 2,5 litros de 
óleo fúsel para cada 1000 litros de etanol [14]. O Brasil produziu 33,1 bilhões de litros de etanol na safra 2018/2019 [15], estima-se uma produção de óleo fúsel de 82,75 milhões de litros.

Diante da ausência de pesquisa da síntese de biodiesel utilizando álcool isoamílico via catálise heterogênea CaOLi. neste trabalho foi sintetizado biodiesel a partir do óleo de soja utilizando álcool isoamílico comercial e CaOLi como catalisador. A conversão de triglicerídeos em ésteres foi avaliada qualitativamente por cromatografia em camada delgada.

\section{Materiais e Métodos}

Os reagentes utilizados foram óleo de soja (SOYA), álcool isoamílico (NEON), ácido acético (GLACIAL), éter de petróleo (CINÉTICA) e éter etílico (ALPHATEC). O catalisador $\mathrm{CaO}$ impregnado com lítio foi sintetizado conforme [7].

A síntese do biodiesel foi realizada um balão de fundo redondo em banho-maria sob uma chapa de aquecimento em diferentes temperaturas $25^{\circ} \mathrm{C}, 65^{\circ} \mathrm{C}$ e $110^{\circ} \mathrm{C}$ sob agitação magnética constante durante $6 \mathrm{~h}$. Acoplado ao sistema um condensador onde circulava água a $15^{\circ} \mathrm{C}$ para evitar a volatização do álcool.

Foi introduzido no balão o álcool numa razão molar álcool:óleo de 9:1, foi adicionada $5 \%$ (massa de catalisador/massa de óleo) de catalisador onde este ficou em agitação durante 1 hora e 30 min para ativação conforme [7], em seguida adicionado o óleo de soja já aquecido. Após decorrido o tempo de reação, a mistura foi colocada num funil de decantação para a decantação da glicerina.

As amostras foram avaliadas qualitativamente através de cromatografia em camada delgada (CCD) com sistema eluente de éter de petróleo, éter etílico e ácido acético na proporção de 18:9:2 (v:v:v), respectivamente revelada com vapor de iodo.

\section{Resultados e Discussão}

Os produtos obtidos nas reações à $25{ }^{\circ} \mathrm{C}$ e $65^{\circ} \mathrm{C}$, Figura $1 \mathrm{~B}$ e $1 \mathrm{C}$, foram semelhantes na CCD ao óleo de soja, ou seja, não houve conversão dos triglicerídeos presentes no óleo em éster (biodiesel).

$\mathrm{Na}$ temperatura de reação à $110^{\circ} \mathrm{C}$ houve formação de biodiesel através da visualização da mancha na região característica de biodiesel na placa de CCD, Figura 1D. Esse resultado é esperado, uma vez que essa temperatura de reação é próxima da temperatura de ebulição do álcool isoamílico, e a literatura já demonstrou amplamente que a conversão da reação de transesterificação é muito favorecida ao ser realizada em temperaturas próximas do ponto de ebulição do álcool utilizado.

Por outro lado, ao final de 6 horas de reação ocorrendo a $110^{\circ} \mathrm{C}$ não se observa a separação de fases. Este mesmo comportamento é relatado por [16] que utilizando $\mathrm{KOH}$ como catalisador para a transesterificação isoamílica do óleo de soja não observou separação entre glicerina e biodiesel.

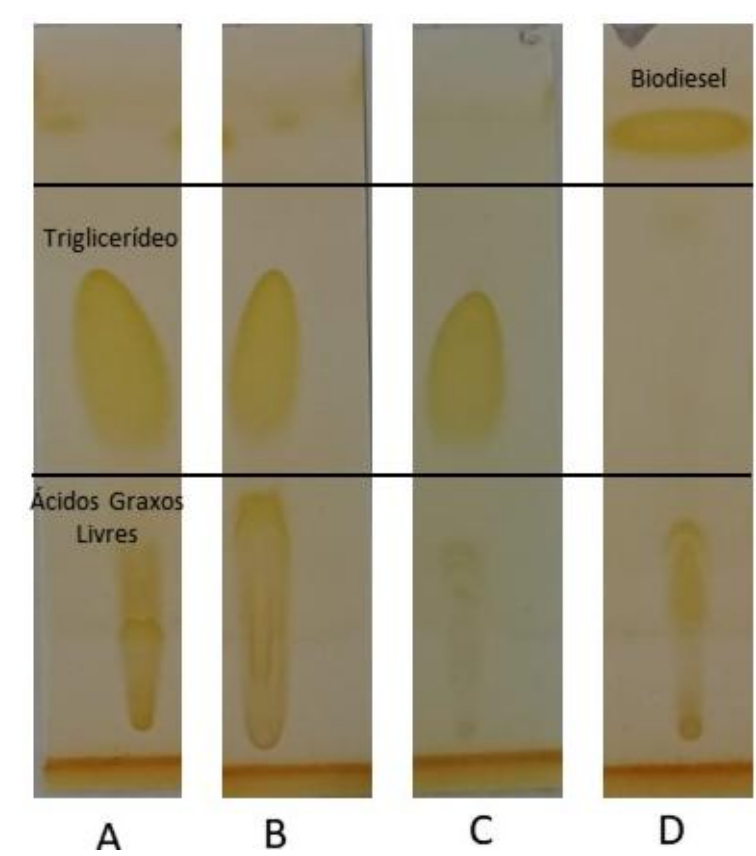

Figura 1: Placa de CCD: A) Óleo de Soja, B) Reação a $25^{\circ} \mathrm{C}$; C) Reação a $65^{\circ} \mathrm{C}$; D) reação a $110^{\circ} \mathrm{C}$.

No produto da reação a $110^{\circ} \mathrm{C}$, Figura 2 , não se observa catalisador precipitado, possivelmente em decorrência da lixiviação do cálcio, o que reduz a vida útil do catalisador e ainda resulta na necessidade de uma etapa de purificação do cálcio lixiviado para que o biodiesel atenda a norma EN 14538 que estabelece uma quantidade de até $5 \mathrm{mg} \cdot \mathrm{Kg}^{-1}$ de cálcio em 
biodiesel comercial. Esta purificação pode ser feita por resina de troca iônica como aponta [17].

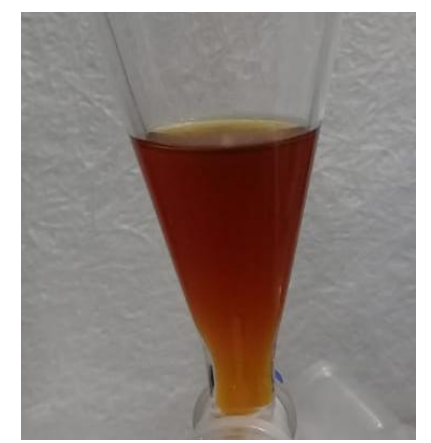

Figura 2: Produto da reação a $110^{\circ} \mathrm{C}$.

A lixiviação do catalisador evidencia que o CaOLi contribuiu para a transesterificação de forma homogênea e heterogênea como observado por [10].

\section{Conclusões}

O CaOLi não apresentou desempenho catalítico nas reações à $25^{\circ} \mathrm{C}$ e $65^{\circ} \mathrm{C}$. Por outro lado, o CaOLi apresentou atividade catalítica à $110^{\circ} \mathrm{C}$ para transesterificação de óleo de soja com álcool isoamílico, com uma possível contribuição homogênea do catalisador.

Trabalhos futuros são necessários para avaliar a qualidade físico-química do biodiesel experimental e quantificar a conversão de triglicerídeo em ésteres

\section{Referências}

[1] ALMEIDA, V. F. et al. Fuel Process. Technol., vol. 133, p. 152-160, 2015.

[2] WAN GHAZALI, W. N. M. et al. Renew. Sustain. Energy Rev., vol. 51, p. 585-602, 2015.

[3] DÁGOSTO. M. D. A. et al. Renew. Sustain. Energy Rev., vol. 43, p. 807-817, 2015.

[4] KUSS, V. V. et al. Renew. Sustain. Energy Rev., vol. 50, p. 1013-1020, 2015.

[5] AVHAD, M. R.; MARCHETTI, J. M. Renew. Sustain. Energy Rev., vol. 50, p. 696-718, 2015.

[6] SHAN, R. et al. Energy Convers. Manag., vol. 127, p. 273-283, 2016.

[7] SOARES, T. M. "ESTUDO DA ADIÇÃO DE LÍTIO A NANOCATALISADORES DE ÓXIDO
DE CÁlCIO PARA A PRODUÇÃO DE BIODIESEL," $86 f$ dissertação (Mestrado em Engenharia Química) Programa de PósGraduação em Engenharia Química. Universidade Federal do Espírito Santo, Alegre, 2018.

[8] KAUR, M.; ALI, A. Renew. Energy, vol. 63, p. 272-279, 2014

[9] KAUR, M.; ALI, A. Renew. Energy, vol. 36, no. 11, p. 2866-2871, 2011.

[10] ALONSO, D. M. et al. Catal. Today, vol. 143, no. 1-2, p. 167-171, 2009.

[11] VERMA, P. et al. Renew. Sustain. Energy Rev., vol. 56, pp. 319-333, 2016.

[12] KIRD R. et al. Biotechnol. Bioprocess Eng., vol. 22, no. 4, pp. 413-422, 2017.

[13] MAYER, F. D. et al. Brazilian J. Chem. Eng., vol. 32, no. 2, pp. 585-593, 2015.

[14] FERREIRA, M. C. et al. Ind. Eng. Chem. Res., vol. 52, no. 6, pp. 2336-2351, 2013.

[15] CONAB, "ACOMPANHAMENTO DA SAFRA BRASILEIRA de cana de açúcar," 2019.

[16] BRANDÃO, M. C. R et al. "Avaliação de catalisadores para a preparação de biodiesel utilizando álcool não convencional". IN I Congresso de Engenharia de Petróleo, Gás Natural e Biocombustível. Campina Grande Paraíba. 2015

[17] JKOUZU, M.; HIDAKA, J. Fuel, v. 105, p. 318324, 2013. 
